JHR

36,1

56

Received 24 January 2020

Revised 10 May 2020

31 May 2020

28 June 2020

Accepted 22 July 2020

\section{Quality of life and associated factors amongst older adults in a remote community, Nepal}

\author{
Saurav Chandra Acharya Samadarshi \\ Faculty of Public Health, Mahidol University, Bangkok, Thailand \\ Pimsurang Taechaboonsermsak \\ Family Health, Faculty of Public Health, Mahidol University, Bangkok, Thailand \\ Mathuros Tipayamongkholgul \\ Department of Epidemiology, Faculty of Public Health, Mahidol University, \\ Bangkok, Thailand, and \\ Korravarn Yodmai \\ Department of Family Health, Faculty of Public Health, \\ Mahidol University Phayathai Campus, Bangkok, Thailand
}

\begin{abstract}
Purpose - The purpose of the study is to assess the quality of life (QOL) of older adults and explore factors associated with it.

Design/methodology/approach - A cross-sectional study was conducted in a remote community in Nepal. A total of 671 older adults aged 60 years were enrolled in the study. QOL was measured by WHOQOL-OLD questionnaire. Data were analyzed using multiple logistic regression.

Findings - Most participants were female (53.0\%), illiterate (70.6\%), married (64.2\%) and living with family $(59.3 \%)$. Among participants, $82.4 \%$ had fair QOL, and the autonomy domain received the lowest score (average $=10.98$ ). After adjusting the model, the elderly aged $<70$ years had 11.07 times better QOL $(\mathrm{aOR}=11.070 ; 95 \% \mathrm{CI}=2.546-48.123)$, elderly with high sufficient income had 2.73 times better QOL $(\mathrm{aOR}=2.738 ; 95 \% \mathrm{CI}=1.183-6.337)$ and elderly free from depression had 9.45 times better $\mathrm{QOL}(\mathrm{aOR}=9.452$; $95 \% \mathrm{CI}=3.466-25.773)$ compared to their counterparts. The elderly receiving social support had 9.97 times better QOL than those who did not ( $\mathrm{aOR}=9.976 ; 95 \% \mathrm{CI}=3.152-31.574$ ), and those able to afford healthcare services had 4.69 times better QOL than those who could not afford it (aOR $=4.694 ; 95 \%$ $\mathrm{CI}=1.046-21.063)$.

Originality/value - The five predictors - age, income sufficiency, depression, social support and healthcare service affordability - were found to significantly affect QOL. This study suggests special care strategies for vulnerable older adults addressing the issues that affect geriatric depression. This article provides relevant information to the government to consider increment of income, encourage family and community for social support and make health services affordable for older adults.
\end{abstract}

Keywords Quality of life, Older adult, Rural community, Active aging, Nepal

Paper type Research paper

\section{Introduction}

The aging population in Nepal has increased to 2.2 million, which is $8 \%$ of the country's overall population, and this trend is increasing every year [1,2]. By 2025, Nepal is estimated to become an aging society and an aged society by 2075 . The change in population dynamics will have

(C) Saurav Chandra Acharya Samadarshi, Pimsurang Taechaboonsermsak, Mathuros Tipayamongkholgul and Korravarn Yodmai. Published in Journal of Health Research. Published by Emerald Publishing Limited. This article is published under the Creative Commons Attribution (CCBY 4.0) licence. Anyone may reproduce, distribute, translate and create derivative works of this article (for both commercial and non-commercial purposes), subject to full attribution to the original publication and authors. The full terms of this licence may be seen at http://creativecommons.org/licences/by/4.0/legalcode 
implications on the healthcare system and economic situation of Nepal which can significantly deteriorate the quality of life (QOL) of the elderly. In order to deal with the situation, the Government of Nepal (GoN) has established senior citizen home care, increased elderly beds in hospitals and implemented the universal health scheme for older adults to improve their QOL [3].

In 2005, the WHO developed a QOL instrument for older persons referred to as the WHOQOL-OLD. Health professionals from 22 countries applied and validated the tool among the elderly [4]. Currently, this tool is used to measure QOL in numerous studies globally [5-12]. Previous studies noted that the survival rates of older people have increased; however, the quality of life (QOL) is substantially low. QOL depends on the social context and place of residence [13-15]. Various studies suggest that QOL varies from place to place based on the social connections and social support individuals receive irrespective of the place of residence [16-19]. Easy access to healthcare services, transportation, long-term care services and other public services supported by the government plays an important role in determining QOL. In Nepal, there is a tendency to migrate from rural to urban areas among the young population which affects the proportion of older adults living alone [20,21].

A study conducted in a municipality of Kathmandu, Nepal, among 462 elderly citizens aged $\geq 70$ years showed that nearly half of them had depression and four-fifths of them had a fair level of QOL. The factors associated with low QOL were increasing age, sex (being female), living alone, low education and unstable economic status. The study showed that an increasing level of depression and QOL score had an inverse correlation between each other [22]. Another study conducted in a rural setting of Nepal among 547 elderly people showed that $19 \%$ of the elderly reported poor QOL. The factors associated with low QOL were age, gender, marital status, living arrangements and physical health [23]. A study in the Morang district of Nepal among 50 elderly people aged $\geq 60$ years living in an old-age home showed low scores of social domain and QOL [24]. Likewise, a study in the Baglung district of Nepal, among 403 elderly citizens $\geq 60$ years, showed that $51.1 \%$ of the elderly had high QOL. The factors associated with QOL included age, gender, marital status, family structure, social capital, neighborhood aesthetic and crime rates [25]. Based on the above evidence observed in the context of Nepal, general characteristics, physical functions, depression, family relationship, social support, health service access and social participation were selected as possible predictors of QOL. From the previous studies, general characteristics including sex, education status, economic condition as well as physical and mental health status were found to be related to QOL.

The social-ecological model derived from the Center for Disease Control and Prevention (CDC) to explore the factors influencing QOL in Nepal was used in this study because this model depicts how contextual and individual factors influence QOL. The original model used four levels that interplay between each other consisting of individual, relationship, community and societal factors [26]. However, for this study, three social-ecological levels were used. Firstly, the study considered the individual-level factors, such as age, sex, education, marital status, income sufficiency, health condition, depression, living arrangement, working status and physical ability. Interpersonal-level factors or relationship factors were considered second, including family relationships and social support. Community-level factors were considered third, referring to health service access and social participation.

Based on previous studies, there is a contrasting relationship between these factors and QOL among older adults. Therefore, this study aims to assess the factors associated with QOL that could potentially inform the policymaking and planning of intervention in order to enhance the QOL of older adults.

\section{Methods}

Study area

A cross-sectional study was conducted in the Thabang Rural Municipality of Rolpa district in Province 5 of Nepal. Rolpa district is situated in Rapti Zone with Liwang as the headquarters,

Quality of life in a remote community 
JHR

36,1

58

with an area of $1879 \mathrm{~km}^{2}$ and constituting 1 municipality and 9 rural municipalities. The study was conducted in one of the rural municipalities from April 2019 to November 2019. The total elderly population of Thabang was 1,308. This area is known as one of the remotest and most conflicted areas of Nepal and ranked in the lowest categories of the human development index (HDI) $(<0.40)$ [27] (see Figure 1).

Study population

The target population was both females and males aged $\geq 60$ years living in the study area at least for a year, having no cognitive and communication impairment and willing to participate in the study. The sample size was calculated by using the Cochran formula [28]. The proportion of high QOL among the elderly living in Nepal was 0.17 [22]. Three of five wards were selected by using a multistage cluster sampling procedure. In the first stage, total households were 417, 494 and 251 in selected ward numbers 1, 3 and, 5 respectively. From the systematic random sampling, 241, 285 and 145 households were selected proportionally from ward number 1, 3 and 5. A ward is the smallest administrative unit in Nepal. Second, households were proportionally allocated to each selected ward according to the number of households. Households were selected randomly from the village name list. Finally, if there were two or more older adults, one was purposively selected. The sample of the study population was 671 .

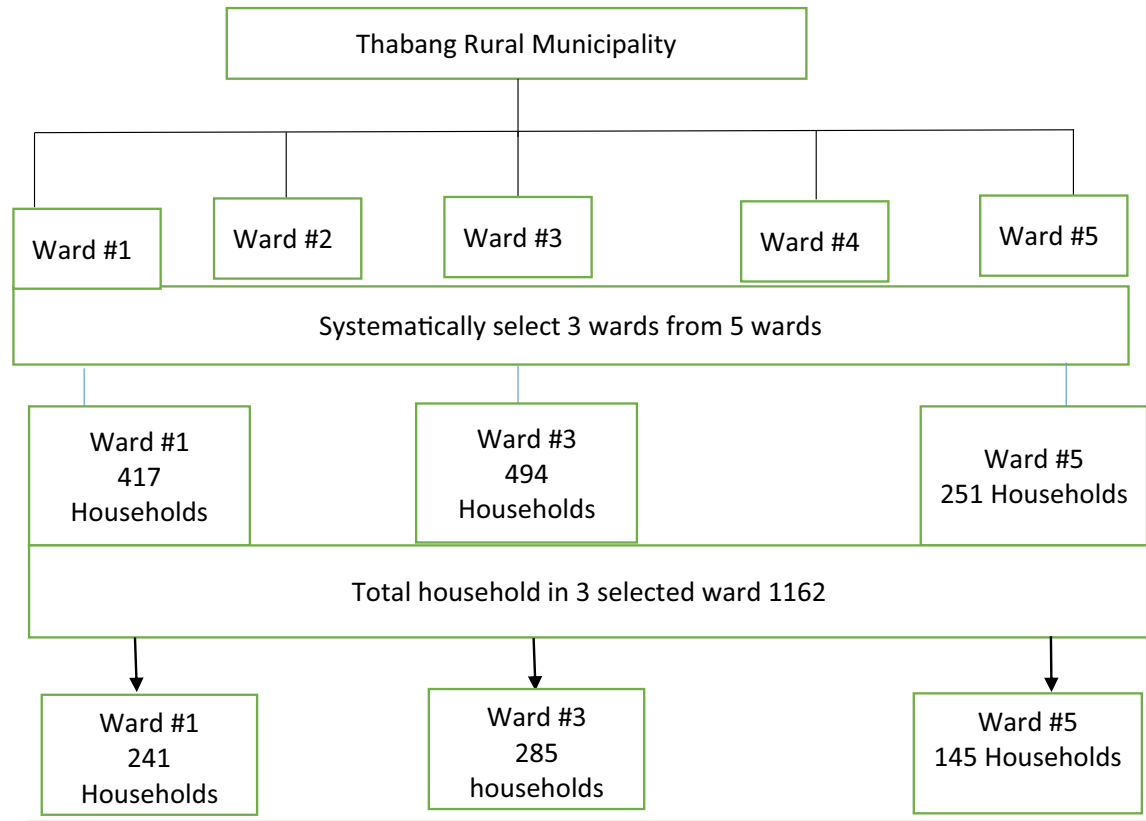

Figure 1.

A diagram of the sampling scheme
671 respondents were selected by systematic random sampling

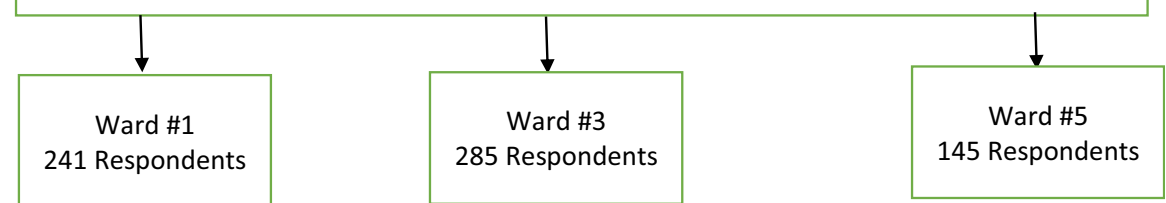




\section{Measurement tools}

Questionnaires used in this study were developed based on theory and literature reviews consisting of six parts. The question content was validated by two experts in the Department of Family Health to confirm whether the questionnaire could measure the objectives of the study. Questionnaires were translated from English to Nepali, and back-translated again to confirm consistency. Tools were pretested on 30 participants with similar characteristics. The Cronbach's alpha of physical function, depression, family relationship, social support, health service access and social participation and QOL were 0.89, 0.91, 0.89, 0.77, 0.80 and 0.77. Data were collected by face-to-face interviews using the structured questionnaires composed of six parts described below.

\section{Individual factor}

Socio-demographic characteristics included age, sex, education, marital status, living arrangement, current working status, income sufficiency and health status. Current chronic illnesses such as hypertension, diabetes and asthma of individuals were also included.

Physical function was assessed by using the activity of daily living by Barthel index of 10 items having a score of $0-3$ and the total score was $0-20$ [29]. The score was divided into 4 categories: total dependent $0-4$, severe $5-8$, moderate $9-11$ and independent 12 and more.

Depression was measured by using a 15-item Geriatric Depression Scale (GDS) [30]. Responses were recorded as either "yes" or "no" to all 15 questions; a value of 1 was assigned to "yes," a value of 0 was assigned to "no" and negative questions were reversely scored. The questions were summed with a range between 0 and 15 points. The score was divided into four categories: less than 5 was no depression, 5-8 mild depression, 9-12 moderate depression and above 12 severe depression [16, 24].

\section{Interpersonal factors}

The family relationship section consisted of 10 items where the scores were recorded as "most of the time," "sometimes" and "never," and values of 2, 1 and 0 were assigned, respectively. The total score ranged from 0 to 20 points. The score was divided into three categories: poor family relationships (0-12), fair family relationships (13-15) and strong family relationships (16 and above).

Social support consisted of a 5-item questionnaire with three answer choices "always," "sometimes" and "never." Values of 2, 1 and 0 were assigned, respectively, and the total score ranged from 0 to 10 points. The score was divided into three categories: poor social support (0-5), fair social support (6-7) and strong social support (8 and more).

\section{Community level}

Health service access was measured using three items: accessibility, availability and affordability of healthcare services [31]. The total score ranged between 0 and 15 . The score was divided into three categories: low access (0-8), moderate access (9-11) and high access (12 and more).

Accessibility consisted of three items and scored 0 if they had no accessibility, and 1 if they had accessibility. The total score was $0-3$ points. If they scored $0-1$, they had no accessibility, and if they scored 2-3, they had accessibility.

Availability consisted of three items which then consisted of three choices: 1,2 and 3 . The total score ranged from 1 to 9 points. It was considered as not available if scored $<6$ points and available if scored $\geq 6$ points.

Lastly, affordability contained three items and a total score between 0 and 6 points. If scored $<5$ points, it was indicated as not affordable, and if scored $5-6$ points, it was indicated as affordable.

Quality of life in a remote community 
JHR

36,1

60

Social participation consisted of 7 items in the questionnaire with three answer choices: "good," "neither good nor bad" and "poor," and values of 3, 2 and 1 were assigned, respectively. The total score ranged between 7 and 2 . The score was divided into 3 categories: poor social participation (0-13), fair participation (14-16) and strong participation (17 and above).

The QOL was measured using WHOQOL-OLD. This model has 24 items of six facets: sensory ability, autonomy, social participation, physical function, death and dying and intimacy facets. The answers were rated on five linked scale ( $0-5$ points). The total QOL score ranged from 24 to 120 points. The total score was divided into three levels: low QOL (scored 24-56 points), fair QOL (scored 57-89 points) and high QOL (scored 90-120 points).

\section{Statistical analysis}

Statistical analysis was performed by using the Statistical Package for the Social Sciences version 18.0. General characteristics of respondents were presented as frequency, percent, mean and standard deviation (SD). Factors associated with the QOL were analyzed by using multiple logistic regression analysis at $95 \% \mathrm{CI}$.

\section{Ethical consideration}

This study was approved by the Ethics Review Committee of the Faculty of Public Health, Mahidol University (31/2562), and Nepal Health Research Council, Nepal (202/2019).

\section{Results}

\section{Characteristics of respondents}

The age of the respondents ranged from 60 to 96 years (mean age 68.6, SD \pm 7.1 ) of which $53.1 \%$ were females. The majority of respondents were illiterate $(70.6 \%)$, and over half of them $(64.2 \%)$ were married. More than half of them lived with family $(59.3 \%)$ followed by $(34.1 \%)$ those living with their spouse and $(6.6 \%)$ living alone. Although $64.7 \%$ were currently working, only $33.1 \%$ had sufficient income for their livelihood for 1 year.

A total of $64.4 \%$ of the study population reported chronic illness, including arthritis $(35.9 \%)$, asthma (29.8\%), hypertension $(7.9 \%)$, diabetes $(2.4 \%)$ and others $(3 \%)$ such as thyroid and cancer. Among them, $86.3 \%$ of them presented independence, while $8.3 \%$ of them were moderately dependent. The majority of the participants reported depression $(79.7 \%)$ of which $35.3 \%$ had severe depression, while $24.4 \%$ had mild and $20 \%$ had moderate depression.

At the interpersonal level, most of the respondents were found to have weak family relationships $(63.8 \%)$, followed by good family relationships $(18.6 \%)$ and decent family relationships $(17.6 \%)$. In terms of social support, the majority of the elderly had weak social support $(77.2 \%)$, followed by those having strong social support $(11.8 \%)$ and fair social support $(11 \%)$.

At the community level, the majority $(80.8 \%)$ had low access to health services, and $19.2 \%$ had high access to health services. Regarding accessibility, $67.1 \%$ had low accessibility and $32.9 \%$ had high accessibility. Regarding the availability of health services, $85.1 \%$ reported low availability, while $14.9 \%$ reported comparatively high availability of health services. Regarding affordability of health service, $87.2 \%$ had high affordability, and $12.8 \%$ had low affordability. In the same way, more than half of the participants had fair social participation (51\%), followed by poor social participation $(28.6 \%)$ and strong social participation $(20.4 \%)$.

\section{Quality of life of older adults}

The majority of older adults reported fair QOL (82.41\%), followed by high QOL (9.84\%) and low QOL $(7.75 \%)$. When classified into each facet, the sensory ability (SAB) averaged score 
11.99 (S.D. $\pm=3.77$ ), the average score of autonomy (AUT) was 10.98 (S.D. $\pm=2.71$ ), the average score of social participation (SOP) was 12.56 (S.D. $\pm=2.77$ ), the average score of pastpresent-future activity (PPF) was 11.92 (S.D. $\pm=2.58$ ), the average score of death and dying (DAD) was 13.74 (S.D. $\pm=2.75$ ) and the average score of intimacy (INT) was 11.88 $(\mathrm{S} . \mathrm{D} \pm=2.73)$.

Factors associated with the quality of life in older adults

Table 1 shows that binary logistic regression was performed to identify the factors associated with QOL in older adults. The results indicated those aged $<70$ years had 5.84 times $(\mathrm{OR}=5.843,95 \%$ CI 2.743-12.449, $p<0.001)$ higher QOL compared with those aged $\geq 70$ years. Males had 3.37 times higher QOL than females $(\mathrm{OR}=3.376,95 \% \mathrm{CI}=1.919-5.939$, $p<0.001)$. The literate elderly had 3.30 times higher QOL compared to the illiterate elderly $(\mathrm{OR}=3.309,95 \% \mathrm{CI}=1.973-5.550, p<0.001)$. Similarly, older married adults had 1.68 times higher QOL than those who were unmarried $(\mathrm{OR}=1.683,95 \% \mathrm{CI}=0.946-2.993, p=0.007)$. Older adults with high sufficient income had 3.90 times higher QOL than those with low sufficient income $(\mathrm{OR}=3.902,95 \% \mathrm{CI}=2.277-6.688, p<0.001)$. Those who were in a nuclear family had higher QOL compared to those with a joint family. (OR $=0.328,95 \%$ $\mathrm{CI}=0.193-0.559, p<0.001)$. With the current working status, older adults who were currently working had higher QOL compared to those who were not working $(\mathrm{OR}=4.416$, $95 \% \mathrm{CI}=2.071-9.416, p<0.001)$.

Activities of daily living (ADL) on the Barthel index showed that $13.7 \%$ of respondents recorded dependent status, and among this group, 100\% of them had low QOL. Among $86.3 \%$ of independent older adults, $88.6 \%$ had low QOL and $9.8 \%$ had high QOL. Binary logistic regression analysis could not be conducted due to small sampling. Older adults who had chronic illness had lower QOL compared to those without chronic illness (OR $=2.925$; $95 \% \mathrm{CI}=1.741-4.916, p<0.001)$. When compared with each disease, the results showed that the older adults with asthma had lower QOL when compared with those without asthma $(\mathrm{OR}=3.370,95 \% \mathrm{CI}=1.578-7.198, p<0.002)$. A similar result was seen in arthritis cases those living with arthritis had lower QOL compared to those without arthritis $(\mathrm{OR}=3.067$, $95 \% \mathrm{CI}=1.573-5.980, p<0.001)$. Although statistically not significant, older adults with hypertension had lower QOL than those without hypertension $(\mathrm{OR}=1.187,95 \% \mathrm{CI}=0.487-$ $2.892, p>0.05)$. Older adults with diabetes had 2.21 times higher QOL compared to those without diabetes $(\mathrm{OR}=2.168,95 \% \mathrm{CI}=0.602-7.815, p>0.05)$. Depression in older adults presented lower QOL compared to older adults without depression $(\mathrm{OR}=42.169,95 \%$ $\mathrm{CI}=20.085-88.525, p<0.001$ ).

At the interpersonal level, older adults who had strong family relationships had 15.31 times higher QOL than those who had a poor family relationship (OR $=15.314, \mathrm{CI}=8.611-$ $27.236, p<0.001)$. Those with strong social support had 44.29 times higher QOL compared to those with poor social support $(\mathrm{OR}=44.294,95 \% \mathrm{CI}=23.337-84.073, p<0.001)$.

At the community level, older adults who had high health service access had 5.30 times higher QOL compared to those with low access $(\mathrm{OR}=5.302, \mathrm{CI}=3.122-9.003, p<0.001)$. In social participation, older adults with strong social participation scores had 4.48 times higher QOL compared to those with poor social participation scores $(\mathrm{OR}=4.482,95 \% \mathrm{CI}=2.647-$ $7.588, p<0.001)$.

\section{Factors predicted to the quality of life in older adults}

Table 2 shows that, based on multiple logistic regression analysis, older adults aged $<70$ years, with income sufficiency, no depression, high social support and affordability of healthcare services were involved in the prediction of the QOL in older adults. Older adults aged $<70$ years were predicted to have 11.07 times higher QOL compared with those aged

Quality of life in a remote community 
JHR

36,1

\begin{tabular}{|c|c|c|c|c|c|}
\hline \multirow[b]{2}{*}{ Variables } & \multicolumn{2}{|c|}{ Quality of life $[n(\%)]$} & \multirow[b]{2}{*}{$p$-value } & \multirow[b]{2}{*}{ OR } & \multirow[b]{2}{*}{$95 \% \mathrm{CI}$} \\
\hline & Low & High & & & \\
\hline $\begin{array}{l}\text { Age (years) } \\
\geq 70 \\
<70\end{array}$ & $\begin{array}{l}270(97.1 \%) \\
335(85.2 \%)\end{array}$ & $\begin{array}{c}8(2.9 \%) \\
58(14.8 \%)\end{array}$ & $<0.001^{*}$ & $\begin{array}{l}\text { Ref } \\
5.843\end{array}$ & $(2.743-12.449)$ \\
\hline $\begin{array}{l}\text { Sex } \\
\text { Female } \\
\text { Male }\end{array}$ & $\begin{array}{l}338(94.9 \%) \\
267(84.8 \%)\end{array}$ & $\begin{array}{l}18(5.1 \%) \\
48(15.2 \%)\end{array}$ & $<0.001^{*}$ & $\begin{array}{c}\text { Ref } \\
3.376\end{array}$ & $(1.919-5.939)$ \\
\hline $\begin{array}{l}\text { Education } \\
\text { Illiterate } \\
\text { Literate }\end{array}$ & $\begin{array}{l}444(93.7 \%) \\
161(81.7 \%)\end{array}$ & $\begin{array}{l}30(6.3 \%) \\
36(18.3 \%)\end{array}$ & $<0.001^{*}$ & $\begin{array}{c}\text { Ref } \\
3.309\end{array}$ & $(1.973-5.550)$ \\
\hline $\begin{array}{l}\text { Marital status } \\
\text { Unmarried } \\
\text { Married }\end{array}$ & $\begin{array}{l}223(92.9 \%) \\
382(88.6 \%)\end{array}$ & $\begin{array}{l}17(7.1 \%) \\
49(11.4 \%)\end{array}$ & 0.077 & $\begin{array}{c}\text { Ref } \\
1.683\end{array}$ & $(0.946-2.993)$ \\
\hline $\begin{array}{l}\text { Income sufficiency } \\
\text { Less sufficient } \\
\text { Highly sufficient }\end{array}$ & $\begin{array}{l}400(94.8 \%) \\
205(82.3 \%)\end{array}$ & $\begin{array}{l}22(5.2 \%) \\
44(17.7 \%)\end{array}$ & $<0.001^{*}$ & $\begin{array}{c}\text { Ref } \\
3.902\end{array}$ & (2.277-6.688) \\
\hline $\begin{array}{l}\text { Physical function } \\
\text { Dependent } \\
\text { Independent }\end{array}$ & $\begin{array}{r}92(100.0 \%) \\
513(88.6 \%)\end{array}$ & $\begin{array}{r}0(0.0 \%) \\
66(9.8 \%)\end{array}$ & & & \\
\hline $\begin{array}{l}\text { Chronic illness } \\
\text { No } \\
\text { Yes }\end{array}$ & $\begin{array}{l}200(83.7 \%) \\
405(93.8 \%)\end{array}$ & $\begin{array}{l}39(16.3 \%) \\
27(6.3 \%)\end{array}$ & $<0.001^{*}$ & $\begin{array}{c}\text { Ref } \\
2.925\end{array}$ & $(1.741-4.916)$ \\
\hline $\begin{array}{l}\text { Hypertension } \\
\text { No } \\
\text { Yes }\end{array}$ & $\begin{array}{r}558(90.3 \%) \\
47(88.7 \%)\end{array}$ & $\begin{array}{c}60(9.7 \%) \\
6(11.3 \%)\end{array}$ & 0.706 & $\begin{array}{c}\text { Ref } \\
1.187\end{array}$ & $(0.487-2.892)$ \\
\hline $\begin{array}{l}\text { Asthma } \\
\text { No } \\
\text { Yes }\end{array}$ & $\begin{array}{l}413(87.7 \%) \\
192(96.0 \%)\end{array}$ & $\begin{array}{c}58(12.3 \%) \\
8(4.0 \%)\end{array}$ & $0.002 *$ & $\begin{array}{c}\text { Ref } \\
3.370\end{array}$ & (1.578-7.198) \\
\hline $\begin{array}{l}\text { Diabetic mellitus } \\
\text { No } \\
\text { Yes }\end{array}$ & $\begin{array}{r}592(90.4 \%) \\
13(81.3 \%)\end{array}$ & $\begin{array}{c}63(9.6 \%) \\
3(18.8 \%)\end{array}$ & 0.237 & $\begin{array}{c}\text { Ref } \\
2.168\end{array}$ & $(0.602-7.815)$ \\
\hline $\begin{array}{l}\text { Arthritis } \\
\text { No } \\
\text { Yes }\end{array}$ & $\begin{array}{l}375(87.2 \%) \\
230(95.4 \%)\end{array}$ & $\begin{array}{l}55(12.8 \%) \\
11(4.6 \%)\end{array}$ & $0.001 *$ & $\begin{array}{c}\text { Ref } \\
3.067\end{array}$ & $(1.573-5.980)$ \\
\hline $\begin{array}{l}\text { Depression } \\
\text { No depression } \\
\text { Depression }\end{array}$ & $\begin{array}{r}79(58.1 \%) \\
526(98.3 \%)\end{array}$ & $\begin{array}{c}57(41.9 \%) \\
9(1.7 \%)\end{array}$ & $<0.001 *$ & $\begin{array}{c}\text { Ref } \\
42.169\end{array}$ & (20.085-88.525) \\
\hline $\begin{array}{l}\text { Living arrangement } \\
\text { Nuclear family } \\
\text { Joint family }\end{array}$ & $\begin{array}{l}230(84.2 \%) \\
375(94.2 \%)\end{array}$ & $\begin{array}{l}43(15.8 \%) \\
23(5.8 \%)\end{array}$ & $<0.001^{*}$ & $\begin{array}{c}\text { Ref } \\
0.328\end{array}$ & $(0.193-0.559)$ \\
\hline $\begin{array}{l}\text { Currently working } \\
\text { No } \\
\text { Yes }\end{array}$ & $\begin{array}{l}229(96.6 \%) \\
376(86.6 \%)\end{array}$ & $\begin{array}{c}8(3.4 \%) \\
58(13.4 \%)\end{array}$ & $<0.001^{*}$ & $\begin{array}{l}\operatorname{Ref} \\
4.416\end{array}$ & $\begin{array}{l}(2.071-9.416) \\
\text { (continued) }\end{array}$ \\
\hline
\end{tabular}

Table 1.

Factors associated with the QOL in older adults by using binary Ye logistic regression analysis

\section{2}




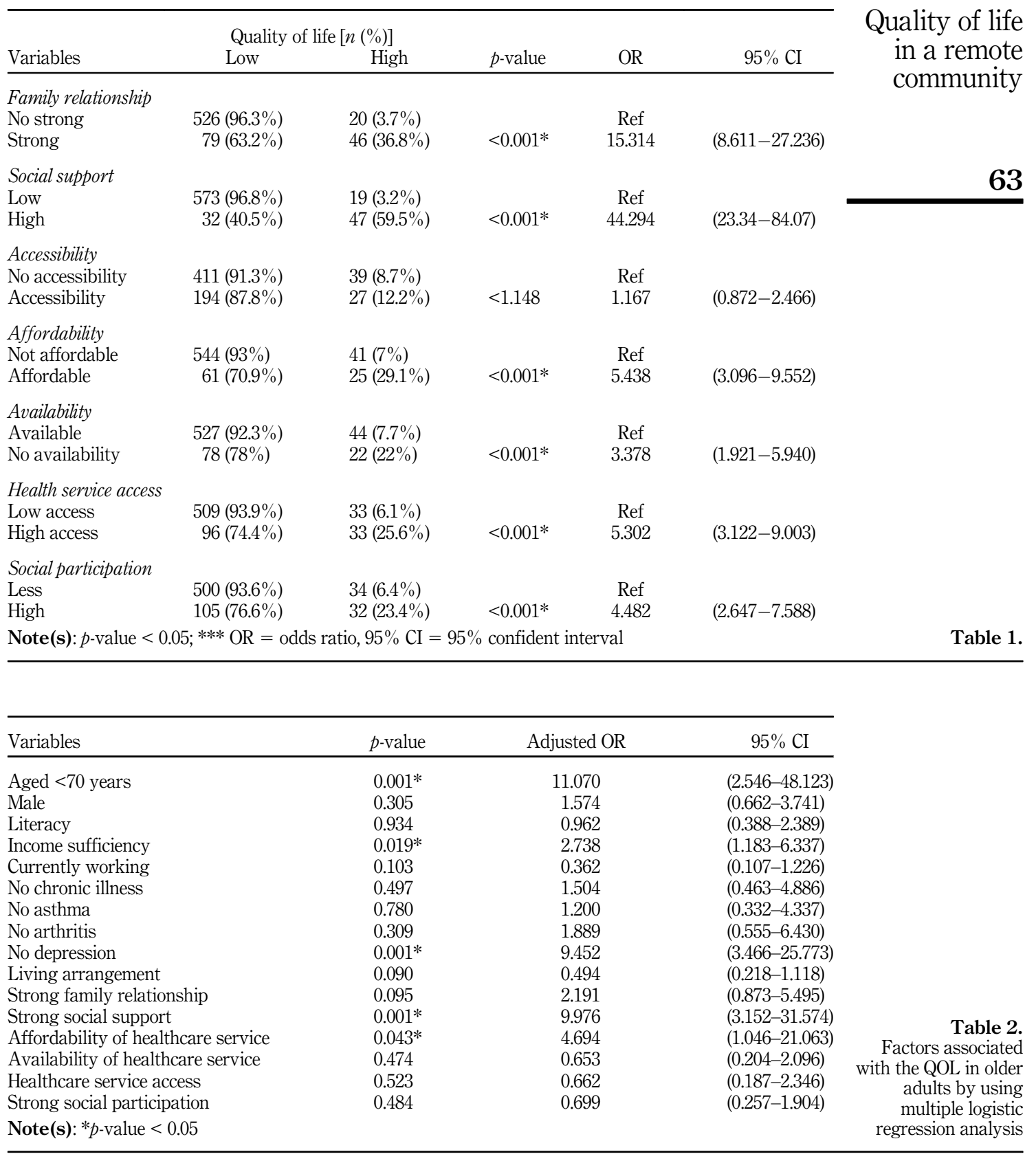

$\geq 70$ years $(\mathrm{aOR}=11.070 ; 95 \% \mathrm{CI}=2.546-48.123, p<0.001)$. For sufficient income, older adults who had high sufficient income were predicted to have 2.73 times higher QOL compared to those who had income insufficiency $(\mathrm{aOR}=2.738 ; 95 \% \mathrm{CI}=1.183-6.337$, 
JHR

36,1

64

$p<0.019)$. Older adults free from depression had 9.45 times higher QOL compared to those who suffered from depression $(\mathrm{aOR}=9.452 ; 95 \% \mathrm{CI}=3.466-25.773, p<0.001)$. At the interpersonal level, the results showed that older adults who received strong social support had 9.97 times higher QOL than those who had poor social support $(\mathrm{aOR}=9.976 ; 95 \%$ $\mathrm{CI}=3.152-31.574, p<0.001$ ). The community level indicated that older adults who could afford health services had 4.69 times higher QOL compared to those who could not afford healthcare services $(\mathrm{aOR}=4.694 ; 95 \% \mathrm{CI}=1.046-21.063, p<0.043)$

This study found that sex (male), literacy, living with chronic illness, living with asthma, living with arthritis, living arrangements, working status, family relationship, availability and accessibility of healthcare services and social participation were not statistically significant predictions for QOL in older adults.

\section{Discussion}

This study showed the relationship between QOL for those aged $<70$ years, with income sufficiency, depression, social support and healthcare service affordability. This study confirmed the multifactorial nature, that is, demographic factors, clinical and behavioral factors that influenced the QOL among the elderly. From previous studies, age is an indicator used to determine self-care ability; old age negatively affects QOL. Self-care decreases when people enter the aging process and heavily rely upon others for daily activities, thus decreasing the QOL. This study suggests that the younger have 11.07 times higher QOL than older age groups, which is similar to the results from previous studies reporting that older adults had low QOL [10,32].

The study found high sufficiency income predicts 2.73 times higher QOL compared to low sufficient income, which is similar to results from earlier studies [22, 32]. Low prevalence of the high QOL and high prevalence of depression in remote communities were identified in this study. However, Nepal is considered a happy country, and yet there is a high proportion of older adults with poor QOL and depression. Therefore, depression occurs commonly and influences the QOL in older adults. In addition, low QOL causes suicidal attempts and suicidal ideation in older adults. It is illustrated that the severity of depression and chronic depression in older adult influence their QOL [8]. Depression is more serious and influences the QOL in older adults with diseases such as HIV/AIDS [33]. However, it seems that depression in older adults is related to poor social support, care and social function [34].

At the interpersonal level, social support was significantly associated with QOL. Strong social support predicted 9.97 times high QOL compared to poor social support. This finding is similar to a study by Belanger and his colleague, which reported that strong social support predicted 1.5 times higher QOL if they received high social support from children and 1.3 times if received from a spouse [34]. Living alone reduced the QOL in older adults compared with those who lived in community dwellings. Results from other studies indicated that strong family relationship and social support create favorable circumstance for those elderly who are living at home. It is predicted that the QOL among elderly who are living in unfavorable circumstances, that is, living at home and with family dysfunction, have low QOL [35]. Social participation was indicated as a predictor of the QOL in older adults, which was similar to previous studies that revealed social participation is statistically significant with QOL [22].

At the community level, affordability of health services is significantly associated with QOL. Elders who could afford healthcare services had 4.69 times higher QOL than those who could not afford health services. A similar study conducted in Bangladesh indicated that health service affordability was found to be positively associated with the QOL of elderly people [36]. 
Based on this study, sex, education, chronic illnesses, living arrangements, family relationships, working status, health service accessibility and social participation were not significant predictors for QOL. However, these factors were found to be associated with QOL in other studies. As compared with earlier studies, the QOL was high in males rather than females but was not found to be statistically significant in this study [11, 12, 22, 37]. A study by Campos indicated that among both genders, those who had a high health rate and did not suffer from depression predicted high QOL. Poor physical activity was associated with QOL among females, but not among males [35]. Furthermore, more physical impairment such as hearing loss can occur in both genders and has serious consequences on the QOL. However, a study by Joanvic found that after fitting hearing aids, both genders had improved their QOL [7].

\section{Conclusion}

This study showed that determinants such as age $<70$ years, income sufficiency, depression, social support and affordability to healthcare services have a strong relation with QOL. Therefore, health professionals and concerned officers should consider these factors while planning to improve the QOL of older adults. Special care strategies focused on providing financial support, routine health checkups, psychosocial counseling, establishing elderly clubs to share life skills and experiences and the establishment of recreational centers should be carried out by the local authorities and government.

Conflict of interest: There is no conflict of interest.

\section{References}

1. Ghimire S, Baral BK, Pokhrel BR, Pokhrel A, Acharya A, Amatya D, et al. Depression, malnutrition, and health-related quality of life among Nepali older patients. BMC Geriatr. 2018; 18(1): 191. doi: 10.1186/s12877-018-0881-5.

2. National Census Citizen Observation Committee [NCOC]. Nepal national population and housing census 2011: observation report. Kathmandu: NCOC; 2012.

3. Bhandari K. Social security system of elderly population in Nepal. NUTA J. 2019; 6(1-2): 18-24.

4. Power M, Quinn K, Schmidt S. Development of the WHOQOL-old module. Qual Life Res. 2005; 14(10): 2197-214. doi: 10.1007/s11136-005-7380-9.

5. Campbell KH, Huang ES, Dale W, Parker MM, John PM, Young BA, et al. Association between estimated GFR, health-related quality of life, and depression among older adults with diabetes: the diabetes and aging study. Am J Kidney Dis. 2013; 62(3): 541-8. doi: 10.1053/j.ajkd.2013.03.039.

6. Fang J, Power M, Lin Y, Zhang J, Hao Y, Chatterji S. Development of short versions for the WHOQOL-OLD module. Gerontologist. 2012; 52(1): 66-78. doi: 10.1093/geront/gnr085.

7. Joanovic E, Kisvetrova H, Nemcek D, Kurkova P, Svejdikova B, Zapletalova J, et al. Gender differences in improvement of older-person-specific quality of life after hearing-aid fitting. Disabil Health J. 2019; 12(2): 209-13. doi: 10.1016/j.dhjo.2018.08.010.

8. Johnson JK, Louhivuori J, Stewart AL, Tolvanen A, Ross L, Era P. Quality of life (QOL) of older adult community choral singers in Finland. Int Psychogeriatr. 2013; 25(7): 1055-64. doi: 10.1017/ S1041610213000422.

9. Sanchez-Garcia S, Gallegos-Carrillo K, Espinel-Bermudez MC, Doubova SV, Sanchez-Arenas R, Garcia-Pena C, et al. Comparison of quality of life among community-dwelling older adults with the frailty phenotype. Qual Life Res. 2017; 26(10): 2693-703. doi: 10.1007/s11136-0171630-5.

10. Seangpraw K, Ratanasiripong NT, Ratanasiripong P. Predictors of quality of life of the rural older adults in Northern Thailand. J Health Res. 2019; 33(6): 450-9. doi: 10.1108/Jhr-112018-0142.
Quality of life in a remote community 
JHR

36,1

66
11. Yodmai K, Somrongthong R. Depression and factors associated with the quality of life among the elderly in Numpong and Somsoong district, Khonkean province, Thailand. Eur J Sci Res. 2016; 138(3): 193-9.

12. Yodmai K, Somrongthong R, Kumar R. Determinants of quality of life among rural elderly population in Khonkean province of Thailand. Journal of the Liaquat University of Medical and Health Sciences. 2018; 17(3): 180-4. doi: 10.22442/jlumhs.181730574.

13. Institute of Medicine. Rebuilding the unity of health and the environment in rural America: workshop summary. Washington, DC: National Academies Press; 2006.

14. Ribeiro CG, Ferretti F, de Sá CA. Quality of life based on level of physical activity among elderly residents of urban and rural areas. Revista Brasileira de Geriatria e Gerontologia. 2017; 20(3): 330-9. doi: 10.1590/1981-22562017020.160110.

15. dos Santos Tavares DM, Fernandes Bolina A, Aparecida Dias F, dos Santos Ferreira PC, José Haas V. Quality of life of elderly. Comparison between urban and rural areas. Invest Educ Enferm. 2014; 32(3): 401-13. doi: 10.17533/udea.iee.v32n3a05.

16. Sewo Sampaio PY, Ito E, Carvalho Sampaio RA. The association of activity and participation with quality of life between Japanese older adults living in rural and urban areas. Journal of Clinical Gerontology and Geriatrics. 2013; 4(2): 51-6. doi: 10.1016/j.jcgg.2012.11.004.

17. Amorim SM, França L, Valentini F. Predictors of happiness among retired from urban and rural areas in Brazil. Psicol Reflex Crit. 2017; 30(1): 2. doi: 10.1186/s41155-016-0055-3.

18. Papaioannou W, Oulis CJ, Yfantopoulos J. The oral health related quality of life in different groups of senior citizens as measured by the OHIP-14 questionnaire. Oral Biol. Dent. 2015; 3(1). doi: 10. 7243/2053-5775-3-1.

19. Usha VK, Lalitha K. Quality of life of senior citizens: a rural-urban comparison. Indian J Soc Psychiatry. 2016; 32(2): 158-63. doi: 10.4103/0971-9962.181104.

20. Baernholdt M, Hinton I, Yan G, Rose K, Mattos M. Factors associated with quality of life in older adults in the USA. Qual Life Res. 2012; 21(3): 527-34. doi: 10.1007/s11136-011-9954-z.

21. Borders TF, Aday LA, Xu KT. Factors associated with health-related quality of life among an older population in a largely rural western region. J Rural Health. 2004; 20(1): 67-75. doi: 10.1111/j. 1748-0361.2004.tb00009.x.

22. Adhikari RD, Ranjitkar UD, Chand A. Factors associated with quality of life of senior citizens residing in Tarakeshwor Municipality, Kathmandu. Int J Health Sci Res. 2018; 8(1): 201-8.

23. Joshi M, Chalise H, Khatiwada P. Quality of life of Nepalese elderly living in rural Nepal. J Gerontol Geriatr Res. 2018; 7(5): 1000484. doi: 10.4172/2167-7182.1000484.

24. Shrestha M, KC H, Bhattarai P, Mishra A, Parajuli SB. Quality of life of elderly people living with family and in old age home in Morang district, Nepal. BIBECHANA. 2019; 16: 221-7. doi: 10.3126/ bibechana.v16i0.21643.

25. Pradeep GC, Tiraphat S, Chompikul J. Factors associated with quality of life among the elderly in Baglung district, Nepal. J Public Health Dev. 2017; 15(3): 51-64.

26. Centers for Disease Control and Prevention [CDC]. The social-ecological model: a framework for prevention. [cited 2020 March 3]. Available from: https:/www.cdc.gov/violenceprevention/ publichealthissue/social-ecologicalmodel.html.

27. Government of Nepal. Nepal human development report 2014. Kathmandu: National Planning Commission, Government of Nepal; 2014.

28. Lemeshow S, Hosmer DW Jr, Klar J, Lwanga SK. Adequacy of sample size in health studies. Chichester: John Wiley \& Sons; 1990.

29. Barthel activities of daily living (ADL) index. Occas Pap R Coll Gen Pract. 1993; 59: 24.

30. Greenberg SA. The geriatric depression scale (GDS). [cited 2020 March 3]. Available from: https:// hign.org/sites/default/files/2020-06/Try_This_General_Assessment_4.pdf. 
31. McLaughlin CG, Wyszewianski L. Access to care: remembering old lessons. Health Serv Res. 2002; 37(6): 1441-3. doi: 10.1111/1475-6773.12171.

32. Hongthong D, Somrongthong R, Ward P. Factors influencing the quality of life (Qol) among Thai older people in a rural area of Thailand. Iran J Public Health. 2015; 44(4): 479-85.

Quality of life in a remote community

33. Selvaraj V, Ross MW, Unnikrishnan B, Hegde S. Association of quality of life with major depressive disorder among people with HIV in South India. AIDS care. 2013; 25(2): 169-72. doi: 10. 1080/09540121.2012.689809.

34. Belanger E, Ahmed T, Vafaei A, Curcio CL, Phillips SP, Zunzunegui MV. Sources of social support associated with health and quality of life: a cross-sectional study among Canadian and Latin American older adults. BMJ open. 2016; 6(6): e011503. doi: 10.1136/bmjopen-2016-011503.

35. Campos AC, Ferreira e Ferreira E, Vargas AM, Albala C. Aging, Gender and Quality of Life (AGEQOL) study: factors associated with good quality of life in older Brazilian communitydwelling adults. Health Qual Life Outcomes. 2014; 12: 166. doi: 10.1186/s12955-014-0166-4.

36. Uddin MA, Soivong P, Lasuka D, Juntasopeepun P. Factors related to quality of life among older adults in Bangladesh: a cross sectional survey. Nurs Health Sci. 2017; 19(4): 518-24. doi: 10.1111/ nhs.12385.

37. Yodmai K, Phummarak S, Sirisuth JC, Kumar R, Somrongthong R. Quality of life and fear of falling among an aging population in semi rural, Thailand. J Ayub Med Coll Abbottabad. 2015; 27(4): 771-4.

\section{Corresponding author}

Pimsurang Taechaboonsermsak can be contacted at: pimsurang.tae@mahidol.ac.th

For instructions on how to order reprints of this article, please visit our website: 